\title{
ANATOMIA DO LENHO DE CESTRUM STRIGILATUM (SOLANACEAE) ${ }^{1}$
}

\author{
MATHEUS XAVIER ${ }^{2}$ PAULO FERNANDO DOS SANTOS MACHADO ${ }^{3}$ \\ JOSÉ NEWTON CARDOSO MARCHIORI ${ }^{4}$
}

\section{RESUMO}

São presentemente descritos os caracteres microscópicos do lenho de Cestrum strigilatum, com base em amostra procedente do Rio Grande do Sul (Brasil). Na estrutura anatômica, salientam-se: a ausência de parênquima axial, fibras septadas apenas junto aos vasos e fibras não septadas no restante do lenho, e pontoações simples alongadas pelo lado do parênquima radial, subtendendo, comumente, duas pontoações areoladas de vaso.

Palavras-chave: Anatomia da Madeira; Cestrum strigilatum; Solanaceae.

\begin{abstract}
[Anatomy of the wood of Cestrum strigilatum (Solanaceae)].

The microscopic features of the wood of Cestrum strigilatum are presently described, based on a sample from Rio Grande do Sul State (Brazil). In the anatomical structure, it is emphasized: the absence of axial parenchyma, septate fibers only close to vessels and non-septate fibers in the rest of the wood, and simple elongated pits by the side of ray parenchyma, usually subtending two bordered pits by the side of the vessel.
\end{abstract}

Key words: Cestrum strigilatum; Solanaceae; Wood Anatomy.

\section{INTRODUÇÃO E REVISÃO DE LITERATU- RA}

Gênero tropical e subtropical com 250 espécies, aproximadamente, Cestrum L. distinguese entre as Solanáceas pelas sementes com embrião reto ou apenas curvado, pela flor com cinco estames e fruto do tipo baga (Cabrera, 1979). A espécie mais conhecida é a dama-da-noite (Cestrum nocturnum L.), arbusto originário das Antilhas e de flores muito perfumadas (Lorenzi \& Souza, 2001), que é a espécie-tipo do gênero (Cabrera, 1979).

Nativo desde a Costa Rica, Panamá, Colômbia e Venezuela, até o noroeste e nordeste da Argentina e o sul do Brasil (Soares et al., 2007),

1 Recebido em 30-07-2018 e aceito para publicação em 20-08-2018.

2 Aluno do Curso de Graduação em Engenharia Florestal, Universidade Federal de Santa Maria (UFSM).

3 Engenheiro Florestal, doutorando do Programa de PósGraduação em Engenharia Florestal da UFSM. barcasole@gmail.com

4 Engenheiro Florestal, Dr. Professor Titular do Departamento de Ciências Florestais da UFSM. marchioricfl@gmail.com
Cestrum strigilatum Ruiz \& Pav. - a popular "coerana-amarela" - é arbusto de até $2 \mathrm{~m}$ de altura, com folhas oblongo-lanceoladas ou elíptico-lanceoladas, inflorescências corimbosas, flores verde-amareladas ou alaranjadas de até $22 \mathrm{~mm}$ de comprimento e bagas elipsóides de $8 \mathrm{~mm}$ de comprimento (Smith \& Downs, 1966). Espécie ruderal, encontrada em todas as formações vegetais do Rio Grande do Sul, apresenta-se com flores e frutos ao longo de todo o ano e segrega-se das demais espécies do gênero, nativas no estado, pelos tricomas dendríticoestrelados, presentes em ramos e folhas (Soares et al., 2007).

A respeito do lenho, Metcalfe \& Chalk (1972) relacionam os seguintes caracteres para a família Solanaceae: vasos de diâmetro muito pequeno a médio, escassos até extremamente numerosos, frequentemente com múltiplos racemiformes e múltiplos radiais de 4 ou mais em algumas espécies, por vezes, em arranjo dendrítico ou padrão tangencial; porosidade em anel e espessamentos espiralados, observados em poucas espécies; pontoações intervasculares alternas, geralmente grandes, mas, por vezes, 
diminutas; pontoações para com parênquima usualmente grandes e alongadas; elementos vasculares de comprimento médio a moderadamente curto; parênquima axial apotraqueal difuso, em curtas faixas unisseriadas ou paratraqueal escasso; raios exclusivamente unisseriados ou com até 8 células de largura, compostos de células quadradas ou eretas, por vezes quase homogêneos e com células pequenas; fibras de comprimento médio a moderadamente curtas, com pontoações simples e paredes finas, mas com pontoações areoladas e paredes espessas em poucas espécies; fibras com finos septos, presentes em alguns gêneros; e canais radiais, presentes em algumas espécies. Para os gêneros Cestrum, Acnistus e Datura, Record \& Hess (1943) referem a ocorrência ocasional de grandes canais radiais abertos.

\section{MATERIAL E MÉTODOS}

O material examinado, composto de amostra de lenho e exsicata botânica, é procedente de Jaguari, RS (Marchiori, J.N.C. no 801, 05-61987) e foi incorporado ao Herbário do Departamento de Ciências Florestais (HDCF) da Universidade Federal de Santa Maria (UFSM) com o n 3176.

Da amostra de lenho foram extraídos três corpos-de-prova com dimensão aproximada de $3 \times 2 \times 1 \mathrm{~cm}$, orientados para a obtenção de cortes anatômicos nos planos transversal, longitudinal radial e longitudinal tangencial; um quarto fragmento serviu para a obtenção de finos palitos, usados na maceração.

Os corpos-de-prova foram fervidos em água, por cerca de 30 horas, e foram seccionados em micrótomo de deslize, obtendo-se cortes dos três planos anatômicos com espessura de 18-20 $\mu \mathrm{m}$. Os cortes foram coloridos com solução aquosa de Acridina-Vermelha e Crisoidina (1\%), num primeiro banho, seguido por banho em Azulde-Astra 1\% (Dujardin, 1964); seguiu-se a desidratação em série alcoólica crescente (álcool etílico 25\%, 50\%, 75\%, 90\%, 95\%), até álcool absoluto (duas vezes), a passagem por xilol e montagem permanente, com resina Entellan.
No preparo de lâminas de macerado, usouse a técnica de Jeffrey (Freund, 1970). A pasta obtida foi corada com safranina, desidratada segundo a mesma sequência alcoólica anteriormente referida e passou por xilol, sempre com o auxílio de papel de filtro e funil. Na montagem de lâminas permanentes, também se usou o mesmo meio de montagem anteriormente referido.

A descrição do lenho seguiu as recomendações do IAWA Committee (Wheeler et al., 1989). A percentagem ocupada pelos distintos tecidos da madeira foi definida em plano transversal e com o uso de um contador de laboratório, mediante 600 determinações ao acaso, conforme Marchiori (1980). Os demais caracteres anatômicos foram medidos em microscópio binocular Carl Zeiss, provido de escala graduada.

As imagens que ilustram o texto foram realizadas em fotomicroscópio Leica (modelo DM 2000), no Laboratório de Botânica Estrutural, do Departamento de Biologia da UFSM.

$\mathrm{Na}$ citação dos caracteres quantitativos, informa-se a média e o desvio padrão, seguido pelos valores mínimo e máximo, entre parênteses.

\section{DESCRIÇÃO MICROSCÓPICA DO LENHO}

Anéis de crescimento: distintos, marcados por camada de 1-4 fibras achatadas em plano transversal (Figura 1A).

Vasos: em porosidade difusa, uniforme. Poros solitários, de seção arredondada (52 \pm 9 (3273) $\mu \mathrm{m}$ ), solitários e em múltiplos radiais e racemiformes de até oito unidades (Figura $1 \mathrm{~A}, \mathrm{~B})$. Elementos vasculares de $568 \pm 122$ (330790) $\mu \mathrm{m}$ de comprimento, com placas de perfuração simples; apêndices curtos, em uma ou em ambas as extremidades. Espessamentos espiralados e estriações, ausentes. Pontoações intervasculares alternas, arredondadas $(6,9 \pm 0,8(5,6$ $8,2) \mu \mathrm{m})$, não ornamentadas e com aberturas estreitas, cruzadas em " $\mathrm{x}$ ", no par (Figura 1F). Pontoações raio-vasculares unilateralmente compostas: simples e radialmente alongadas $(9,8$ 
$\pm 2,5(6,3-12,5) \mu \mathrm{m})$, pelo lado do parênquima radial, subtendendo, comumente, duas pontoações areoladas no lado do vaso (Figura 1C). Tiloses, ausentes; depósitos, não observados no material examinado.

Parênquima axial: ausente.

Raios: em número de $11 \pm 2,7$ (7-15) por mm, compondo $29,5 \pm 5,04$ (26-38) \% do volume da madeira. Os unisseriados $(25 \pm 9,1(16-41) \%$ do total), de $433 \pm 185$ (60-860) $\mu$ m e $6 \pm 1,9$ (4-11) células de altura, compostos de células eretas e quadradas. Os multisseriados, em sua maioria trisseriados $(27,5 \pm 3,6(21-32) \%)$, menos comumente bisseriados $(22,7 \pm 5,9$ (13$29) \%)$ e tetrasseriados $(20,2 \pm 5,2(12-27) \%) \mathrm{e}$ escassos com mais de quatro células de largura $(4,7 \pm 2,3(3-7) \%)$; de $750 \pm 159$ (450-1050) $\mu \mathrm{m}$ de altura, com $17 \pm 3,3$ (14-24) células, e 57 $\pm 12,3$ (30-80) $\mu \mathrm{m}$ de largura, compostos de células quadradas, eretas e escassas curtoprocumbentes em cada raio, dispostas na parte central e que contrastam das demais, em plano tangencial, por sua seção arredondada (Figura $1 \mathrm{E}$ ), uma vez que a maioria (quadradas e eretas) tem seção longo-ovalada neste plano anatômico (Figura 1E). Em plano radial, as abundantes pontoações simples conferem à parede das células radiais o aspecto de contas de rosário. Células envolventes, abundantes na margem de raios e subtendendo 2-3 células internas, comumente. Cristais romboédricos de oxalato de cálcio, freqüentes em células quadradas e eretas. Células perfuradas, células oleíferas e células mucilaginosas, ausentes.

Fibras: proeminentes, representando $53 \pm 2,7$ (50-56) \% do volume da madeira, reunindo fibras libriformes septadas e não septadas; as primeiras, menos abundantes, encontram-se, sobretudo, na proximidade de vasos. Fibras de $890 \pm$ 126 (650-1175) $\mu \mathrm{m}$ de comprimento, com 19,8 $\pm 2,7(15-23) \mu \mathrm{m}$ de diâmetro e paredes finas a médias $(3,9 \pm 0,76(1,9-5,6) \mu \mathrm{m})$.

Outros caracteres: variantes cambiais, tubos laticíferos e taniníferos, floema incluso, canais intercelulares e estratificação, ausentes; mácu- las medulares não observadas no material examinado.

\section{ANÁLISE DA ESTRUTURA ANATÔMICA}

Os caracteres anatômicos do lenho de Cestrum strigilatum se enquadram com as possibilidades estruturais referidas por Metcalfe \& Chalk (1972) e Record \& Hess (1943) para a família Solanaceae. Como peculiaridades anatômicas, salientam-se: a ausência de parênquima axial, compensada pela presença de fibras septadas nas proximidades de vasos; as pontuações raio-vasculares simples e alongadas, pelo lado do parênquima, que subtendem, comumente, duas pontoações areoladas, pelo lado do vaso; e os raios heterogêneos (com células quadradas, eretas e curto-procumbentes) de até 4 células de largura, com células envolventes, vistas em plano tangencial.

Do referido por Record \& Hess (1943) para os gêneros Cestrum, Acnistus e Datura, há que registrar-se que no lenho de Cestrum strigilatum não se observaram canais intercelulares radiais.

\section{LITERATURA CITADA}

CABRERA, A.L. Solanaceae, Solanáceas. In: BURKART, A. Flora Ilustrada de Entre Rios (Argentina). Buenos Aires: I.N.T.A., 1979. p. 346-452.

DUJARDIN, E.P. Eine neue HolzZellulosenfaerbung. Mikrokosmos, n. 53, p. 94 , 1964.

FREUND, H. Handbuch der Mikroskopie in der Technik. Frankfurt: Umsham Verlag, 1970, $379 \mathrm{p}$.

LORENZI, H.; SOUZA, H.M. de. Plantas ornamentais do Brasil: arbustivas herbáceas e trepadeiras. Nova Odessa: Instituto Plantarum, 2001. p. 1006.

MARCHIORI, J.N.C. Estudo anatômico do xilema secundário e da casca de algumas espécies dos gêneros Acacia e Mimosa, nativas no estado do Rio Grande do Sul. 1980. 186f. Dissertação (Mestrado em Engenharia Florestal) Universidade Federal do Paraná, Curitiba, 1980. 

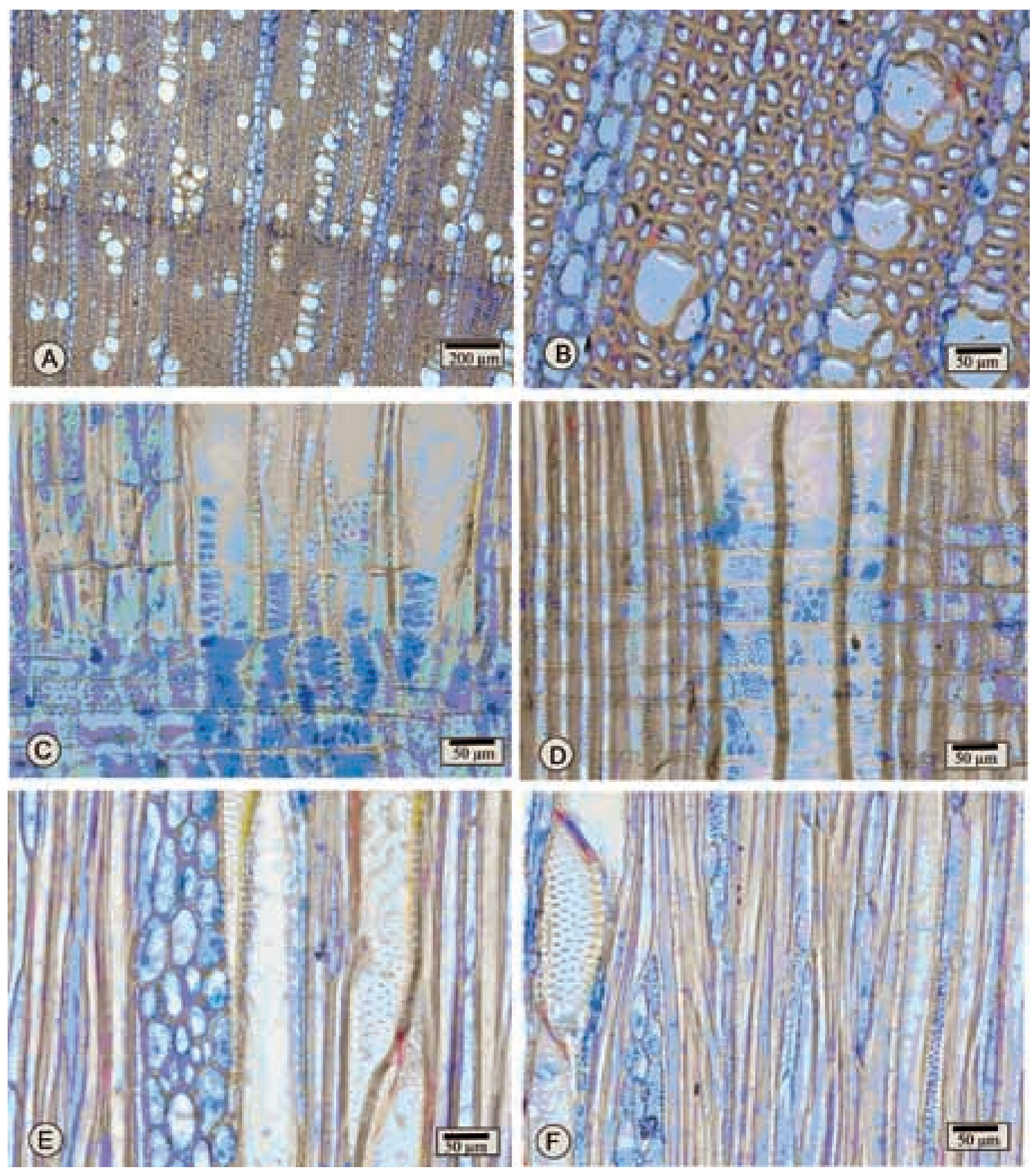

FIGURA 1 - Aspectos anatômicos do lenho de Cestrum strigilatum. A - Anel de crescimento distinto, porosidade difusa e poros em múltiplos radiais, menos comumente solitários e em múltiplos racemiformes (seção transversal). B - Poros de seção arredondada, fibras e raios uni e multisseriados (seção transversal). C-Pontoações raio-vasculares unilateralmente compostas, comumente alongadas na direção radial (seção longitudinal radial). D - Pontoações raio-vasculares unilateralmente compostas, alongadas, e células radiais com abundantes pontoações, conferindo aspecto de "contas de rosário" à parede (seção longitudinal radial). E - Fibras em sua maioria não septadas, pontoações intervasculares alternas e raios uni e multisseriados; o tetrasseriado (a esquerda da foto ), com células mais isodiamétricas, ao centro, e células envolventes, na margem (seção longitudinal tangencial). F - Fibra septada à direita da foto, ao lado de raio unisseriado. 
METCALFE, C.R.; CHALK, L. Anatomy of the Dicotyledons. Oxford: Clarendon Press, 1972. p. 965-978.

RECORD, S.J.; HESS, W. Timbers of the New World. New Haven: Yale University Press, 1943. p. 514-515.

SMITH, L.B.; DOWNS, R.J. Solanáceas. In: REITZ, P.R. Flora Ilustrada Catarinense. Itajaí: Herbário Barbosa Rodrigues, 1966. p. 325-327.
SOARES, E.L. de C.; VIGNOLI-SILVA, M.; MENTZ, L.A. O gênero Cestrum L. (Solanaceae) no Rio Grande do Sul, Brasil. Pesquisas, Botânica, São Leopoldo, n. 58, p. 263-282, 2007.

WHEELER, E.A.; BAAS, P.; GASSON, P.E. IAWA list of microscopic features for hardwood identification. IAWA Bulletin, v. 10, n. 3, p. 218359, 1989. 